\title{
Soil moisture initialization effects in the Indian monsoon system
}

\author{
S. Asharaf, A. Dobler, and B. Ahrens \\ Institute for Atmospheric and Environmental Sciences, Goethe University, Frankfurt, Germany \\ Received: 31 December 2010 - Revised: 23 May 2011 - Accepted: 6 June 2011 - Published: 14 June 2011
}

\begin{abstract}
Towards the goal to understand the role of land-surface processes over the Indian sub-continent, a series of soil-moisture sensitivity simulations have been performed using a non-hydrostatic regional climate model COSMO-CLM. The experiments were driven by the lateral boundary conditions provided by the ERA-Interim (ECMWF) reanalysis. The simulation results show that the pre-monsoonal soil moisture has a significant influence on the monsoonal precipitation. Both, positive and negative soil-moisture precipitation (S-P) feedback processes are of importance. The negative S-P feedback process is especially influential in the western and the northern parts of India.
\end{abstract}

\section{Introduction}

The Earth's surface plays a key role in weather and climate because of the large energy and water exchange with the overlying atmosphere (Zhang et al., 2004). The water reaching the land surface is distributed into soil water storage, runoff, or recycled into the atmosphere by evapotranspiration. Exchange of radiation, sensible heat, latent heat, and momentum has direct impacts on the wind vector, precipitation, and surface soil (Sellers, 1991). Hence, a proper understanding of the land atmosphere interaction is necessary.

The present work focuses on the investigation of the soil moisture-precipitation (S-P) feedback process over the Indian region. The structure of this paper is as follows. Section 2 presents the model setup, and experimental design. The results and discussion are addressed in Sect. 3 and followed by conclusions (Sect. 4).

\section{Model and experimental design}

The simulations are performed with the non-hydrostatic limited-area climate model COSMO-CLM (Dobler and Ahrens, 2008). As model input, the initial and lateral boundary conditions are taken from the ERA-Interim reanalysis. In the present study, the model horizontal resolution is set to $0.25^{\circ}$ with 32 vertical layers. The simulation domain encompasses the entire Indian region (Fig. 1). More de- tails about the model are given at the community website (http://www.clm-community.eu/).

In order to assess the influence of soil moisture, we have performed several simulations: a reference simulation (CTL) for the period 1989 to 2007 and perturbed simulations. For each year on 2 April, there is a DRY run with an initialized soil $50 \%$ drier and a WET run which is $50 \%$ wetter than CTL (with perturbations limited by the field capacity and the wilting point of the soil type). These perturbations are small in absolute terms, as the pre-monsoonal soils are dry. However, the pre-monsoonal perturbation allows for the investigation of the impacts on the simulated monsoon. The perturbed experiments are driven by the same lateral boundary condition as CTL. Therefore, these set of experiments explain the soil water initialization impacts to the model simulations at the regional scale, as well as at the Indian summer monsoon scale. This setup is motivated by Schär et al. (1999) and Pielke Sr. et al. (1999).

\section{Results and discussions}

The simulations are carried out over the Indian sub-continent for the period 1989 to 2007, where a spin-up time of one year is neglected in the subsequent analysis to mitigate the initial value errors. The present analysis is focused on 1990 to 2007 for the seasonal average (June to September, JJAS) of monthly accumulated monsoonal precipitation. 
Table 1. Mean values of (JJAS, 1990 to 2007) moisture influx (IN), precipitation efficiency ( $\chi$ ), and recycling ratio ( $\beta$ ). Changes in precipitation $(\Delta \mathrm{P})$ between the perturbed and the control simulations as defined in Eq. (1) are also shown.

\begin{tabular}{|c|c|c|c|c|c|c|c|c|c|c|c|c|c|}
\hline \multirow[t]{2}{*}{ Region } & \multicolumn{3}{|c|}{$x$} & \multicolumn{3}{|c|}{$\beta$} & \multicolumn{3}{|c|}{$\begin{array}{c}\text { IN } \\
(\mathrm{mm} / \mathrm{month})\end{array}$} & \multicolumn{2}{|c|}{$\begin{array}{c}\Delta \mathrm{P}_{\text {WET-CTL }} \\
(\mathrm{mm} / \mathrm{month})\end{array}$} & \multicolumn{2}{|c|}{$\begin{array}{c}\Delta \mathrm{P}_{\mathrm{DRY}-\mathrm{CTL}} \\
\text { (mm/month) }\end{array}$} \\
\hline & WET & CTL & DRY & WET & CTL & DRY & WET & CTL & DRY & Direct & Indir. & Direct & Indir. \\
\hline$E$ & 0.51 & 0.49 & 0.49 & 0.14 & 0.13 & 0.12 & 440 & 437 & 427 & 5.0 & 7.0 & -7.0 & 3.0 \\
\hline W & 0.22 & 0.18 & 0.17 & 0.14 & 0.09 & 0.08 & 184 & 198 & 206 & -1.3 & 7.5 & 1.0 & -3.0 \\
\hline $\mathrm{N}$ & 0.53 & 0.51 & 0.51 & 0.29 & 0.23 & 0.21 & 144 & 156 & 158 & 0.8 & 3.9 & -1.3 & 0.5 \\
\hline $\mathrm{CE}$ & 0.30 & 0.29 & 0.29 & 0.10 & 0.09 & 0.09 & 481 & 483 & 479 & 0.5 & 3.1 & -1.6 & -1.5 \\
\hline
\end{tabular}

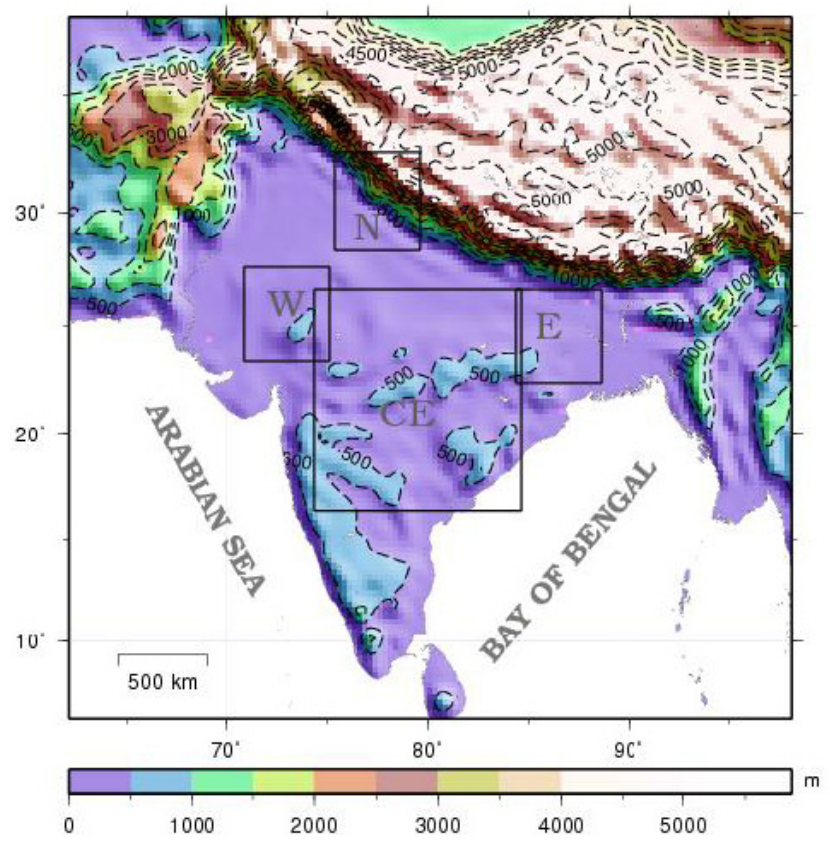

Figure 1. Simulation domain and analysis domains $\mathrm{N}, \mathrm{W}, \mathrm{CE}$ and E. The shading and contour lines show the model orography.

The sensitivity of summer monsoon rainfall with response to the change in initial soil moisture is shown in Fig. 2. The precipitation changes between the WET and CTL experiments are about $+10 \%$ to $+20 \%$ in the eastern region, while they are larger than $+40 \%$ over the northwest part of India. These spatial variations in precipitation are related to the available water in the soils (Kim and Wang, 2007) and to the regional circulations as discussed in the following paragraph. Apart from this, some places, especially the northern Himalayan foothills and the Thar desert (northwest part of India) indicate a negative S-P feedback process, which is consistent with the Bowen ratio (not shown).

The wet (dry) soil moisture perturbations cause an increment (decrement) in the surface pressure by cooling (warming) of the Earth surface through the partitioning of the surface heat fluxes. As a result, there is a decrement (increment) in the geopotential height in the middle of the troposphere (Fig. 3). These local changes especially over the northwestern region further modify the large scale circulation as shown by vertically integrated moisture flux vectors. Decrement in the geopotential height at $500 \mathrm{hPa}$ (Fig. 3) can be depicted by the increasing surface pressure over the northwestern region in the WET experiment. This change (increment in the surface pressure) caused a decrement in transportation of water vapor from the Arabian Sea to the northwest region in the wet soil condition.

To study the land-atmosphere interaction quantitatively, we have calculated the recycling ratio $\beta=\mathrm{ET} /(\mathrm{ET}+\mathrm{IN})$ and precipitation efficiency $\chi=\mathrm{P} /(\mathrm{ET}+\mathrm{IN})$ following Schär et al. (1999), where ET is evapotranspiration, IN influx and P precipitation. For the analysis we have divided the Indian domain into four sub-regions: East (E), West (W), Central (CE), and North (N), as depicted in the Fig. 1. Figure 4 shows the considerable inter-annual variation in the recycling ratio and precipitation efficiency of the CTL and the soil moisture sensitivity simulations (WET and DRY) for the analysis domains $\mathrm{E}$ and $\mathrm{W}$. Here, the bulk characteristics $\beta$ and $\chi$ are predominantly increasing and decreasing in a regular way. In general, the recycling ratios are in the range of 0.1 to 0.4 with largest values for the northern region (cf. Table 1).

The precipitation efficiency $\chi$ is of moderate sensitivity to the soil moisture initialization in most of the years with a small positive feedback. However, some years (e.g., 1992 in E, 1993 in W) experience a negative feedback to soil moisture initialization perturbation. This result is opposite to the results in Schär et al. (1999), where $\chi$ always increases with an increment in the initial soil moisture.

The precipitation changes in the sensitivity experiments (WET and DRY) are estimated by the following equation (see Schär et al., 1999):

$\Delta \mathrm{P}=\chi^{\prime}(\Delta \mathrm{ET}+\Delta \mathrm{IN})+\Delta \chi(\mathrm{ET}+\mathrm{IN})$

Where' denotes the perturbed simulation case and the $\Delta$ terms indicate differences between the perturbed and the control simulations. The first term on the right hand side of the Eq. (1) reflects the precipitation change through direct (recycling) process and the second term depicts the indirect 

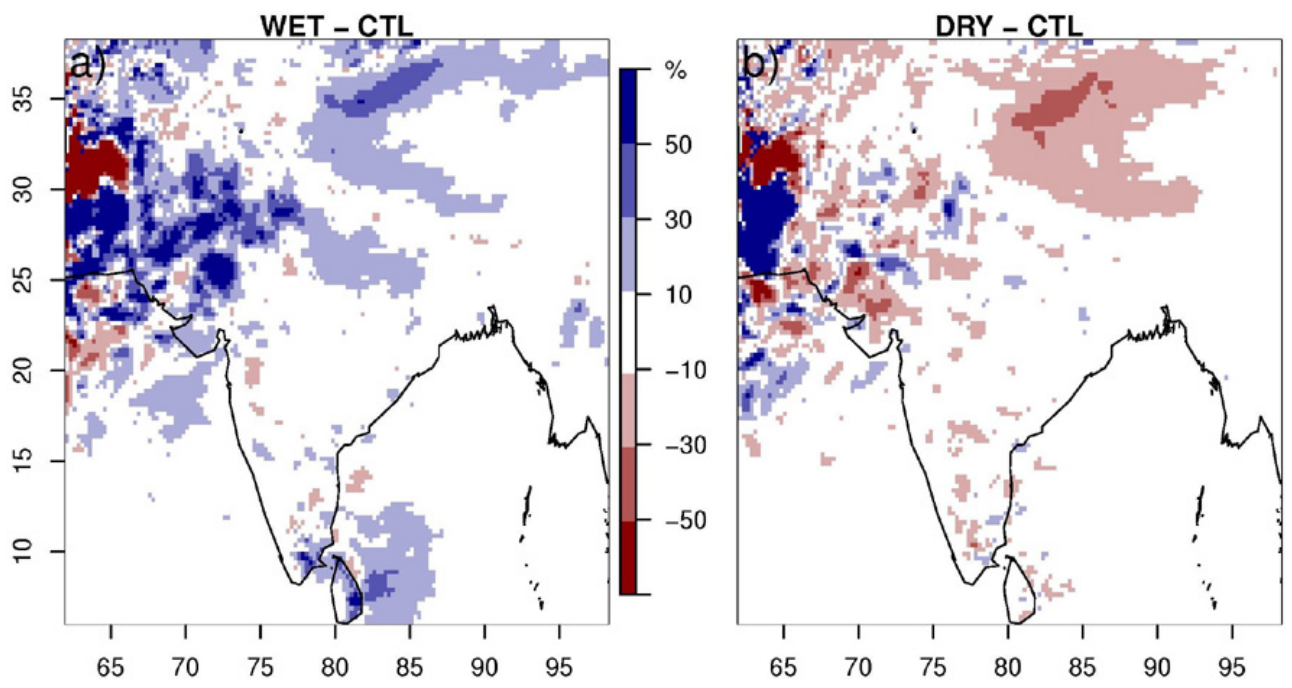

Figure 2. Average summer monsoon (JJAS, 1990 to 2007) relative precipitation difference (in percent) in the WET (left) and DRY (right) experiments relative to the CTL experiment. The red color represents less precipitation and the blue color represents more precipitation than the CTL precipitation.
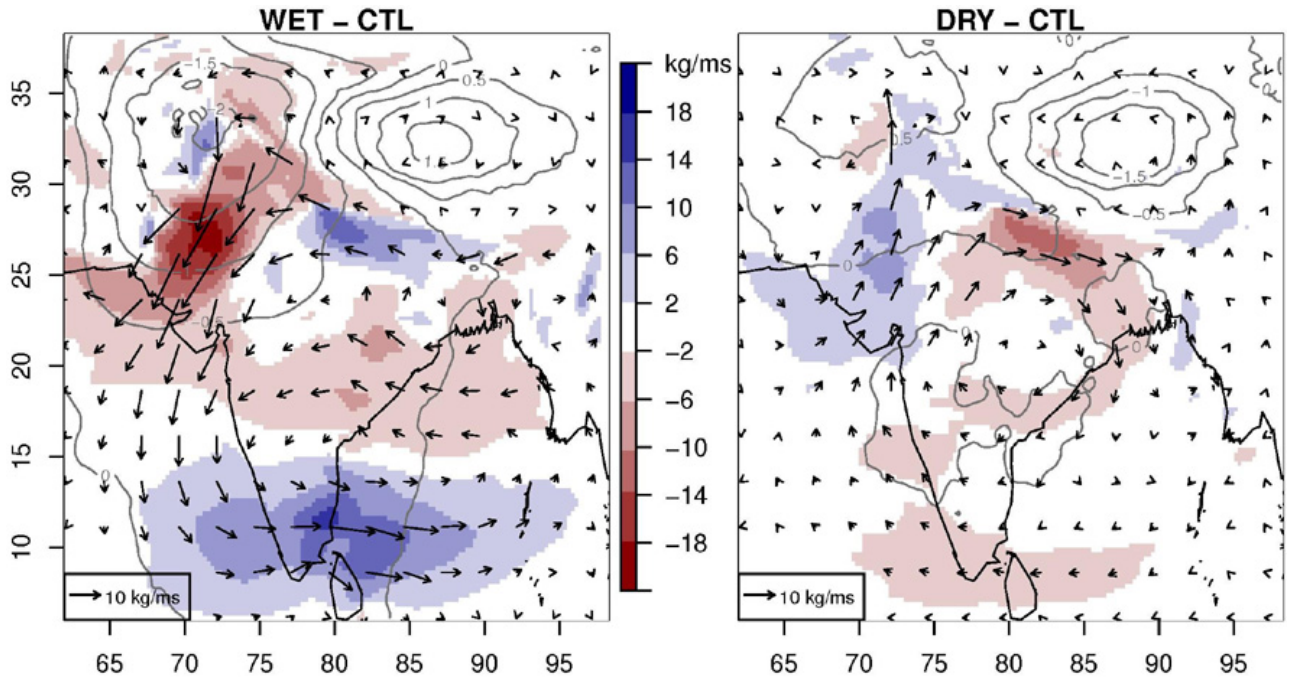

Figure 3. Average summer monsoon (JJAS, 1990 to 2007) vertically integrated moisture flux differences (shaded and vector) and geopotential height differences at $500 \mathrm{hPa}$ (contour, isoline distance $0.5 \mathrm{~m}$ ) in the WET (left) and DRY (right) experiments relative to the CTL experiment.

(feedback) contribution. The results for the different analysis domains (Fig. 1) are made comparable by normalization following Zangvil et al. (2010).

Figure 5 represents the time series of the aforementioned (direct and indirect) processes for the sub-regions $\mathrm{E}$ and $\mathrm{W}$. The results show that the changes in the monsoonal precipitation are clearly dominated by the indirect process in most of the years. The direct recycling process, however, dominates in some of the years, especially in the eastern analysis region E. In this region, the years, e.g., 1992, 1999, 2000, contain higher magnitudes of the direct process than the in- direct process. This high magnitude of the direct process in dry soil conditions can be linked with the high influx differences. Here, the influx differences with respect to the CTL are around $-10 \mathrm{~mm} \mathrm{month}^{-1}$ and $+3 \mathrm{~mm} \mathrm{month}^{-1}$ in dry and wet soil conditions respectively. Often wet soil enhances precipitation and vice versa (positive feedback). But a negative feedback process is also present in all sub-domains, which is more pronounced in the western region. In this case, the drier soil leads to the higher sensible heat flux and an expansion of the boundary layer, which may in turn lead to increased rainfall (Collini et al., 2008). On the other hand, moist conditions 

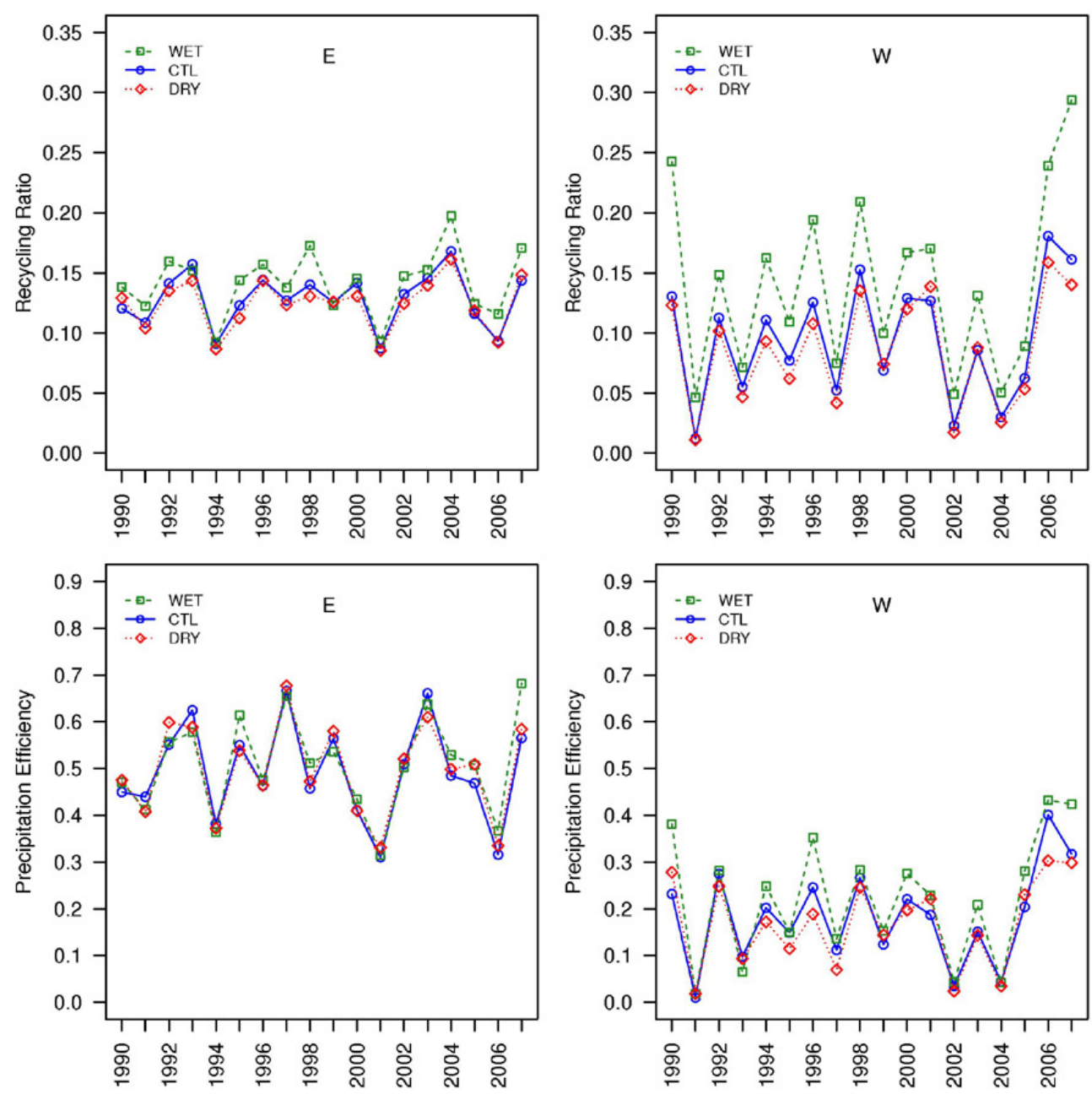

Figure 4. Inter-annual variation of recycling ratio and precipitation efficiency averaged over the monsoon season (JJAS) in the analysis domains East (E) and West (W).

stabilize the atmosphere, inhibiting the vertical movement of air parcels, and as a result decrease in rainfall is observed (Cook et al., 2006).

\section{Conclusions}

Precipitation recycling and feedback processes were investigated through perturbation simulations with the COSMOCLM over India. The results suggest that soil moisture has significant impact on the precipitation formation. In the simulations in which the initial soil moisture is increased by a factor of two (WET), a decrease in the surface Bowen ratio, and thereby a surface cooling was observed. This cooling may be responsible for weakening the strength of moisture transportation from Arabian Sea to the northwest region (Fig. 3). Furthermore, the moisture budget has been examined for different sub-regions to interpret the leading factor as precipitation originating from local evapotranspiration (direct process) or being advected from external sources (indi- rect). As a first result, the Indian summer monsoon contains both processes, where the dominant one varies spatially and temporally. The direct process is more pronounced in the dry soil conditions for the eastern analysis region $\mathrm{E}$, whereas in the wet experiment, the precipitation is controlled by the indirect process. Additionally, the decreasing moisture influx with the increasing soil moisture is related to a negative S-P feedback process, which is more frequent in the western and the northern Indian regions than in the other two regions.

Acknowledgements. The authors acknowledge funding from the Hessian Initiative for the Development of Scientific and Economic Excellence (LOEWE) through the Biodiversity and Climate Research Centre (BiK-F), Frankfurt am Main. The COSMO-CLM community for providing the model and the German Climate Computing Center (DKRZ) for supporting part of the calculation. The authors also thank two anonymous referees, as well as Herbert Formayer (Topical Editor) for their constructive comments and suggestions to the manuscript. 

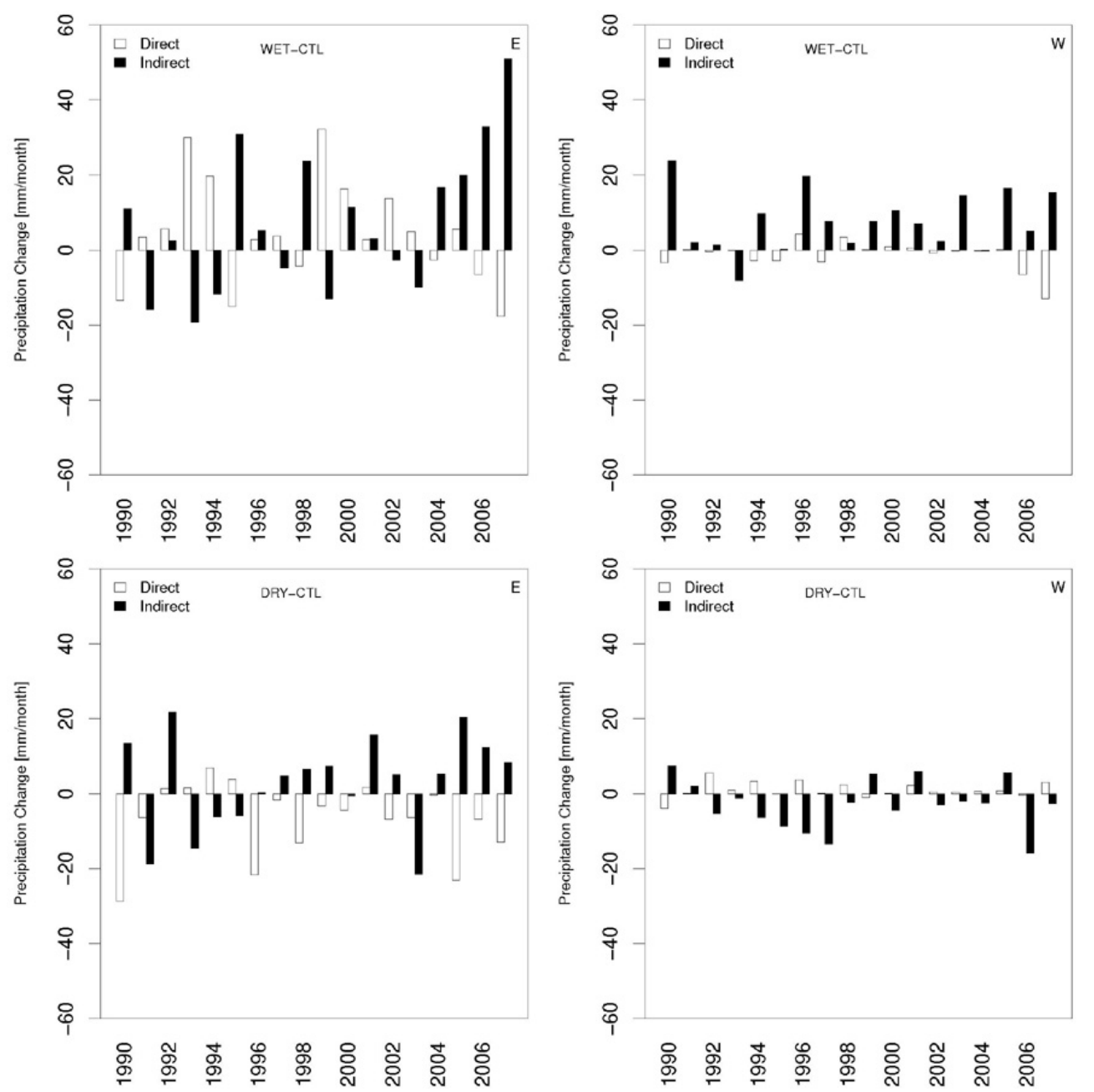

Figure 5. Inter-annual changes in monsoonal rainfall (JJAS) by direct $\chi(\Delta \mathrm{ET}+\Delta \mathrm{IN})$ and indirect effects $\Delta \chi(\mathrm{ET}+\mathrm{IN})$ for WET-CTL (upper) and DRY-CTL (lower) in the analysis domains $\mathrm{E}$ and W.

Edited by: H. Formayer

Reviewed by: two anonymous referees

SC $\mid$ nat $\begin{aligned} & \text { The publication of this article is sponsored } \\ & \text { by the Swiss Academy of Sciences. }\end{aligned}$

\section{References}

Collini, E. A., Berbery, E. H., Barros, V. R., and Pyle, M. E.: How does soil moisture influence the early stages of south American Monsoon?, J. Climate, 21, 195-213, 2008.

Cook, B. I., Bonan, G. B., and Levis, S.: Soil moisture feedback to precipitation in southern Africa, J. Climate, 19, 4198-4206, 2006.

Dobler, A. and Ahrens, B.: Precipitation by a regional climate model and bias correction in Europe and South Asia, Meteorol. Z., 17(4), 499-509, 2008.
Kim, Y. J. and Wang, G. L.: Impact of initial soil moisture anomalies on subsequent precipitation over North America in the coupled land-atmosphere model CAM3-CLM3, J. Hydrometeor., 8, 534-550, 2007.

Pielke Sr., R. A., Listan, G. E., Eastman, J. L., and Lu, L.: Seasonal weather prediction as an initial value problem, J. Geophys. Res., 104, 19463-19479, 1999.

Schär, C., Lüthi, D., and Beyerle, U.: The soil-precipitation feedback: A processes study with a regional climate model, J. Climate, 12, 722-741, 1999.

Sellers, P.: Modeling and observing land-surface-atmosphere interaction on large scale, Surv. Geophys., 12, 85-114, 1991.

Zangvil, A., Lamb, P. J., Portis, D. H., Jin, F., and Malka, S.: Comparative study of atmospheric water vapor budget associated with precipitation in Central US and eastern Mediterranean, Adv. Geosci., 23, 3-9, doi:10.5194/adgeo-23-3-2010, 2010.

Zhang, H., McGregor, J. L., Seller, A. H., and Katzfey, J. J.: Impacts of land surface model complexity on a regional simulation of a typical synoptic event, J. Hydrometeorol., 5, 190-198, 2004. 